\title{
The Impact of COVID-19 Pandemic on Problematic Smartphone Using Among Adolescents
}

\author{
Shuyi Bian ${ }^{1, *}$ \\ ${ }^{1}$ College of Letters and Science, University of California, Davis, United States, CA 95616 \\ *Corresponding author. Email: sbian@ucdavis.edu
}

\begin{abstract}
Until today, the impact of the COVID-19 pandemic still exists. This pandemic has greatly changed people's lifestyles, one of them is a significant increase in frequency and duration of people's use of mobile phones and other electronic products. This article reviewed peer-reviewed articles and other resources on mobile phone addiction and tried to find the impact of the pandemic on Problematic Smartphone Using among adolescents. As a result, stay-at-home order, online social networking, family background, negative emotion, and psychological pressure correlate with problematic smartphone using, while the effect of age and gender are still under debate. Also, problematic smartphone using is related to declining grade, sleep problems, physical problems, and mental health problems.
\end{abstract}

Keywords: problematic smartphone use, smartphone addiction, adolescent, COVID-19

\section{INTRODUCTION}

The COVID-19 pandemic, caused by the SARS-CoV2 virus, has had a profound and significant impact on human beings. Until September 6, 2021, according to data from the World Health Organization, the pandemic has led to $220,383,954$ confirmed cases and 4,561,446 deaths [1]. To deal with this terrible disease, governments have urgently enacted plans and policies based on recommendations of the World Health Organization and respective circumstances, including but not limited to appeal social distancing and compulsory mask policies, call for reducing unnecessary trips, command companies to let employees work at home, and restrict international flights. These self-quarantine policies push people to change most of the things that used to be offline to online, including social connection. As an important vehicle of social contacts in modern society, duration and frequency of mobile phones have inevitably increased [2]. Therefore, the growing using rate of mobile phones has made the problematic smartphone using a hot topic of concern.

Problematic smartphone use, which is also called smartphone addiction, has currently no uniform definition. A previous study defines it as "an inability to regulate one's use of the mobile phone, which eventually involves negative consequences in daily life (e.g., financial problems)" [3]. There are a lot of research focusing on adolescents' problematic smartphone using, but most of the studies started before the COVID-19 pandemic; there are also some research focusing on the impact of the pandemic on problematic smartphone using, whereas few of them specifically focus on adolescent age group. Therefore, this paper attempts to review research on adolescents' problematic smartphone using before the pandemic and research on the impact of the pandemic on problematic smartphone using to explore how the COVID-19 pandemic affects problematic smartphone using in young people, what would be possible consequences and what are practicable interventions.

\section{FACTORS AFFECTING PROBLEMATIC SMARTPHONE USING}

\subsection{Age and Gender}

Whether age and gender have an effect on problematic smartphone using, and whether they have an interaction effect on problematic smartphone using are still controversial, which means different researchers use different measurements to obtain incompatible results. A Korean experiment recruits college students as participants and the results show that female is more likely to have problematic smartphone using and have a tendency to be addicted than male [4]. Another study focusing on undergraduate students in the United States, however, does not find a significant relationship between 
gender and smartphone addiction [5]. Similar to gender, the effect of age is also still under debate. In an experiment, researchers found that young individuals are more likely to have problematic smartphone using [6]; whereas another study does not find a significant association between age and smartphone addiction [7]

\subsection{Stay-at-home Order}

When it comes to the impact of the COVID-19 pandemic, the stay-at-home order, or lockdown, must be one of the most impressive. Cooperating with it is a working-at-home policy and online classes announced by companies and schools. In order to prevent people from gathering in public areas and being infected by the virus, governments have formulated different stay-at-home orders adapted to their own conditions: some places have set curfews, some have called on people to avoid going out except buying necessities, and some have imposed compulsory, complete lockdown due to severe epidemics. Because of these policies, people must keep staying at home and cannot go out to meet friends, enjoy afternoon tea or go out for sports. Scarce entertainment makes more people put more energy on the Internet, and the most hands-down tool for accessing the Internet is a smartphone. In a recent survey conducted at the University of Jordan, $85 \%$ of participated undergraduate students reported that their smartphone use time during lockdown increased to varying degrees, and $42 \%$ of them also reported they used smartphones for more than six hours a day [8].

The reason for this might be that availability of mobile phones during online classes has increased significantly. In an offline classroom, students will restrain their desire to use smartphones because they recognize that they are in an atmosphere of class and study; while taking online classes at home, especially courses with a large number of students, having recordings or not requiring students to turn on the webcamera, it is easy to lose impulse control and use a smartphone for a long time. Since smartphones can help adolescents temporarily escape from tedious classes and assignments and pass boring stay-at-home periods [9], problematic smartphone using will gradually become a more serious problem during the pandemic period.

\subsection{Online Social Networking}

A mentioned in previous part, the COVID-19 virus greatly limits people's offline social activities in any form, no matter it is just a date of a couple or a party of a large group of friends, because social isolation can avoid mass infection to the greatest extent [10]. Thus, it forces people to cease all offline activities. Nonetheless, at this difficult time, reduced interpersonal interaction will make people more vulnerable to loneliness [11]. Hence it becomes important to find ways to keep in touch with close friends online. Fortunately, as a portable technical product, smartphone has easily solved this difficulty. Mobile phone has many applications and functions to help people stay connected, for example, making calls, sending messages, browsing social networking sites like Twitter, Facebook or WhatsApp. At the same time, it is more portable than large equipment like computers and tablets. Smartphone's convenience enables it to become the most suitable substitute for face-to-face social interaction. Mobile phones can help people gain social connection while maintaining physical distance, and alleviate the loneliness symptoms during the pandemic $[11,12]$.

However, the hope to communicate with friends and close ones and the rejecting to be lonely make problematic smartphone using become a greater hidden danger. A study from South Korea showed that although both chatting and playing games on smartphone can predict whether an individual is likely to have smartphone addiction, the use of social networking site (SNS) is more predictive than games that seems more predictive in common sense [13].

\subsection{Family Background}

There is no doubt that the family environment has a great influence on adolescent's development. Susan McHale, a professor of human development of the Social Science Research Institute at The Pennsylvania State University, states that the time that adolescents spend with their families is crucial to both their physical and psychological development [14]. In addition, during the COVID-19 period, due to stay-at-home orders and online working/online classes, the time that teenagers spend with their parents has increased a lot. Thus, the family environment may have a stronger impact on them. A study from China shows that parental rejection, denial, spoiling, interference and over-protection all make adolescents more likely to become addicted to mobile phones [15]. Another study from South Korea shows that both parental addictive behaviors (including alcohol, drugs, and gambling addiction) and domestic violence are significantly related to adolescents' mobile phone addiction [16]. In addition to these effects, parents' problematic smartphone using will also affect adolescents' mobile phone using. A study from China investigates the influence of parents phubbing on children's mobile phone addiction. Phubbing refers to behaviors that focusing on mobile phones and failing to care about or neglecting other people and things; while parents' phubbing refers to a phenomenon that parents spend too much time or only care about using mobile phones and ignore their children. Through questionnaires and surveys of middle school students, the researchers found that adolescents with parents having more parents phubbing tendencies tend to have problematic smartphone using compared with peers [17]. 


\subsection{Negative Emotions and Psychological Pressure}

In addition to possible harm to people's physiological health, the COVID-19 pandemic undoubtedly also has a certain degree of negative impact on people's mental health. Jamil Zaki, an associate professor of psychology at Stanford University, believes that physical distancing during the pandemic makes people feel lonelier, and loneliness will make people more susceptible to stress, negative emotions, and mental illness [11]. Faced with the deprivation of face-to-face social interaction and the panicking unknown virus, even adults may feel helpless, not to mention adolescents who are already susceptible to mental illness; therefore, adolescents may be more vulnerable to stress and mental illness during the COVID-19 period $[18,19]$.

To confront stress, people may choose to use mobile phones more to escape difficult reality and relieve stress. Adolescents, who are more likely to be affected by stress, compared with adults, are more likely to have problematic smartphone using because this can help them relieve negative emotions such as anxiety, depression, loneliness, helplessness, and boredom [9]. Several pieces of research have presented that both stress and mental illness are associated with the problematic smartphone using. A cross-sectional study conducted in South Korea shows that people who are prone to be depression or anxiety, or people who are suffering from depression or anxiety are more likely to have problematic smartphone using [20]. Another study also mentions that stress will make people more probable to have smartphone addiction [13]. Therefore, during the pandemic, stress might also be a significant factor that leading young people to have problematic smartphone use.

\section{CONSEQUENCES OF PROBLEMATIC SMARTPHONE USING}

\subsection{Declining grade}

Students may use mobile phones during classes, which will inevitably make them unable to focus on classes and finally lead to a decline in academic performance. Before the outbreak of the COVID-19, scholars had already paid attention to the connection between mobile phone use and students' academic performance. Studies find that students' academic performance (normally measured by GPA) is significantly negatively correlated with mobile phone use $[21,22]$. When students are using those applications, their attentions are more inclined to contents on new posts of their friends and interesting trends. Thus, they cannot focus on lecture content and materials in the class. Moreover, using social software to communicate with friends will make the students' working memory unable to process the contents in the lecture [22].

\subsection{Physical Health Problems}

Long-time smartphone usage may bring some diseases or pains to adolescents that would not appear at their age. A study shows that long-term use of mobile phones may lead to musculoskeletal pain, and the most common syndromes are neck pain and shoulder pain. In addition, this study also finds that users with larger mobile phone screens tend to have more severe waive pain [23]. Because the size and weight of mobile phones are very small, even physically immature adolescents can use their smartphones with one hand. Another study found that using a mobile phone with one hand may lead to repeated contraction of certain muscles and make neck and shoulder more vulnerable to suffer from musculoskeletal disorder; for people who get used to playing mobile phones with their right hands, the longer they use the mobile phone, the easier it is to have pain in the right shoulder and right thumb [24].

Problematic smartphone users who spend too much time on their mobile phones may also have some physical problems due to unhealthy lifestyles. Compared with people with no or low mobile phone addiction tendency, people with high addiction tendency have fewer exercises and daily walking steps. Besides, they have higher fat mass and less muscle mass in their bodies, even if they have no significant difference in body weight [25]. During the COVID-19 pandemic, because sports grounds are closed, exercise time gets diminished. Excessive use of mobile phones will increase sedentary time, disrupt the original exercise plan, further reduce exercise time, and increase the risk of cardiovascular diseases [9].

\subsection{Sleep Problems}

Many studies have shown that overuse of mobile phones can lead to sleep deficiency in adolescents. They are in a period of changing sleep patterns [18]. If they overly focus on mobile phones due to the pandemic and stay-at-home order, sleep deficiency might lead to more serious consequences than the lack of sleep in adults because adolescents are more vulnerable to sleep deprivation [26]. Research conducted in northwestern Switzerland records some public high school students' sleep time and sleep-habit-related questionnaires. The results show that students with mobile phones are more likely to use phones to chat, send messages, checking SNS on beds when they should go to sleep; they also sleep later than students without mobile phones. Some student participants report various sleeping problems, for example, they feel tired during the day because of playing on mobile phones before going to bed, their sleep quality is degraded, and they feel difficult falling asleep. A more noteworthy result is that this study finds a positive relationship between playing mobile phones before going to bed and depression [18]. 


\subsection{Mental Health Problems}

The outbreak of the COVID-19 pandemic will make people feel lonely, depressed, and have other negative emotions [19]. Adolescents are at an important stage of development and are vulnerable to mental illness [27]. Some studies have found relationships between problematic smartphone use and mental illness like depression or anxiety. A study that uses a web-based questionnaire finds a significantly positive correlation between depression and smartphone addiction [28]. Another study using a two-wave longitudinal survey also finds that smartphone dependency can predict adolescents' future loneliness and depression [27]. A scientific review collects and reviews 23 peer-reviewed papers, summarizes that problematic smartphone using and depression are constantly correlated [29].

It is worth noting that almost all the studies above describe a correlational rather than causational relationship. In other words, it is currently uncertain whether mental illness leads to problematic smartphone use, or problematic smartphone use causes mental illness, or they are a cycle.

\section{INTERVENTION}

Many applications on mobile phones, such as social networking, online games, and online shopping, enable people to better alleviate pressure from the pandemic, maintain social interactions during physical isolation, and satisfy other needs for people's daily lives. These conveniences greatly increase the time using mobile phones, while they also increase the risk of problematic smartphone using. However, many mobile phone users do not realize that they are in this crisis, or even ignore their overuse of mobile phones. Therefore, scholars point out that if no action is taken, problematic smartphone using may become a public health challenge [30]. For those who suspect that they or those around them have mobile phone addiction tendencies, the situation is still not optimistic. Currently, there is no official definition of mobile phone addiction or problematic smartphone using, which may make them feel helpless and miss opportunities to seek help from a counselor or hospital.

At present, the number of studies about intervention on problematic smartphone using is relatively small compared with those on internet addiction and gaming addiction. Fortunately, these interventions have been quite effective. Research shows that mindfulness cognitive-behavioral group therapy can significantly improve impulsivity and anxiety levels of students with smartphone addiction tendencies [31]. Another study shows that group mindfulness-based cognitivebehavioral intervention (GMCI) alleviates symptoms of mobile phone addict users and reduces the time they spend using mobile phones [32]. Except these therapies based on cognitive-behavior therapy, a study finds that for those problematic smartphone users who are not aware of their problems or refuse to change, motivational interviewing (MI) might be a good choice; also, because smartphone addiction including physical symptoms like neck or shoulder pain, the researcher also suggests that exercise rehabilitation therapy might help relieve physical symptoms of smartphone addiction [33].

In addition to finding a counselor to have an intervention, some daily habits and behaviors can also help people to prevent problematic smartphone using. A study points out that physical exercise may be the easiest way to prevent mobile phone addiction. Sports can help young people release negative emotions, strengthen their bodies, and replace mobile phones as a way to maintain interpersonal relationships with peers [9]. Therefore, schools and teachers should encourage young people to do more sports. When adolescents spend time with their families, monitoring regularly enables parents to prevent adolescents from becoming addicted to mobile phones. Parental monitoring was significantly negatively correlated with mobile phone addiction among middle school students. When parents monitor their children, parents phubbing does not contain a significant relationship with their children [17].

\section{CONCLUSION}

This paper attempts to explore the impact of the COVID-19 pandemic on adolescents' problematic smartphone using by reviewing several published peerreviewed articles and other contents. Stay-at-home-order policy, social networking, family conditions, and psychological stress may all act as factors that increase adolescents' possibility to have problematic smartphone using in different ways than before the pandemic. At the same time, as a result, these factors may relate to a decline in academic performance and induction of musculoskeletal pain, poor sleep quality, and various psychological problems. This paper reveals that problematic smartphone using, a problem that should get the public's attention, may cause more serious consequences in different aspects during the COVID-19 pandemic, and calls on people and governments to pay attention to this public health problem.

\section{AUTHORS' CONTRIBUTIONS}

This paper is independently completed by Shuyi Bian.

\section{ACKNOELEDGMENTS}

I would like to express my special thanks of gratitude to my mentor Cuihong Wang who helped me a lot during this project. And I would also like to thank my parents and friends who supported me in finalizing this project within the limited time frame. 


\section{REFERENCES}

[1] World Health Organization. WHO coronavirus (COVID-19) Dashboard. Sep 6, 2021. https://covid19.who.int/.

[2] Sebire, K. The coronavirus lockdown is forcing us to view "screen time" differently. That's a good thing. Apr 13, 2020. The Conversation. https://theconversation.com/the-coronaviruslockdown-is-forcing-us-to-view-screen-timedifferently-thats-a-good-thing-135641.

[3] Billieux, J. Problematic use of the mobile phone: A literature review and a pathways model [J] Current Psychiatry Reviews, 8(4), 2012, pp. 299-307.

[4] Choi, S.-W., Mok, J. Y., Kim, D.-J., Choi, J.-S., Lee, J.-W., Ahn, H.-J., Choi, E.-J., \& Song, W.-Y., Latent class analysis on internet and smartphone addiction in college students [J] Neuropsychiatric Disease and Treatment, 2014, pp. 817-828.

[5] Matar Boumosleh, J., \& Jaalouk, D. Depression, anxiety, and smartphone addiction in university students- a cross sectional study [J] PLOS ONE, 2017,12(8).

[6] Rush, S. Problematic use of smartphones in the workplace: an introductory study [D] BArts (Honours) thesis, Central Queensland University, Rockhampton, 2011.

[7] Demirci, K., Orhan, H., Demirdas, A., Akpinar, A., \& Sert, H., Validity and reliability of the turkish version of the smartphone addiction scale in a younger population [J] Klinik Psikofarmakoloji Bülteni-Bulletin of Clinical Psychopharmacology, 24 (3), 2014, pp.226-234.

[8] Saadeh, H., Al Fayez, R. Q., Al Refaei, A., Shewaikani, N., Khawaldah, H., Abu-Shanab, S., \& Al-Hussaini, M. Smartphone use among university students during covid-19 quarantine: An ethical trigger [J] Frontiers in Public Health 9:600134, 2021.

[9] Luo, J., The Impact of Smart Phone Addiction on Teenager's physical and Mental Health [J] Journal of Neijiang Normal University, vol.34, no.2, 2019, pp.17-21.

[10] Centers for Disease Control and Prevention. How to protect yourself \& others. Aug. 13, 2021. https://www.cdc.gov/coronavirus/2019ncov/prevent-getting-sick/prevention.html.

[11] DeWitte, M. Instead of Social Distancing, Practice "Distant Socializing" Instead, Urges Stanford Psychologist. Stanford News. Mar 19, 2020. http://news.stanford.edu/2020/03/19/try-distantsocializing-instead/

[12] David, M.E.; Roberts, J.A. Smartphone Use during the COVID-19 Pandemic: Social Versus Physical Distancing [J] Int. J. Environ. Res. Public Health, 2021, 18 (3), 1034.

[13] Jeong, S.-H., Kim, H. J., Yum, J.-Y., \& Hwang, Y. (2016). What type of content are smartphone users addicted TO?: SNS vs. games [J] Computers in Human Behavior, 54, 2016, 10-17.

[14] Messer, A. E. Time with parents is important for teens' well-being. July 28, 2017 https://news.psu.edu/story/147370/2012/08/21/rese arch/time-parents-important-teens-well-being.

[15] Wang, P. Sun, J. Wang, Y. The Relationship Between Mobile Phone Addiction, Loneliness, and Parental Rearing Styles of College Students [J] Contemporary Education Sciences, no. 1, 2015, pp. 56-58.

[16] Kim H-J, Min J-Y, Min K-B, Lee T-J, Yoo S. Relationship among family environment, selfcontrol, friendship quality, and adolescents' smartphone addiction in South Korea: Findings from nationwide data [J] PLoS ONE, 2018, 13(2): e0190896.

[17] Ding, Q., Zhang, Y., Zhou Z. The relationship Between Parents Phubbing and High School Students' Mobile Phone Addiction: The Moderating Effect of Parental Monitoring [J] Chinese Journal of Special Education, 1st Issue, 2019 (Serial No.223).

[18] Lemola, S., Perkinson-Gloor, N., Brand, S., DewaldKaufmann, J. F., \& Grob, A. Adolescents' electronic media use at night, sleep disturbance, and depressive symptoms in the smartphone age [J] Journal of Youth and Adolescence, 2014, 44(2), 405-418.

[19] Orben, A., Tomova, L., \& Blakemore, S.-J. The effects of social deprivation on adolescent development and mental health $[\mathrm{J}]$ The Lancet Child \& Adolescent Health, 2020, 4(8), 634-640.

[20] Matar Boumosleh J., Jaalouk D. Depression, anxiety, and smartphone addiction in university students- A cross sectional study [J] PLoS ONE, 2017, 12(8): e0182239.

[21] Maqableh, M., Rajab, L., Quteshat, W., Masa'deh, R.M.T., Khatib, T. and Karajeh, H. The Impact of Social Media Networks Websites Usage on Students' Academic Performance [J] Communications and Network, 2015, 7, 159-171.

[22] Junco, R., \& Cotten, S. R. No A 4 U: The relationship between multitasking and academic 
performance [J] Computers \& Education, 2012, 59 (2), 505-514.

[23] Kim, H.-J., \& Kim, J.-S. The relationship between smartphone use and subjective musculoskeletal symptoms and university students $[\mathrm{J}]$ Journal of Physical Therapy Science, 2015, 27 (3), 575-579.

[24] Lee, M., Hong, Y., Lee, S., Won, J., Yang, J., Park, S., Chang, K.-T., \& Hong, Y. The effects of smartphone use on upper extremity muscle activity and pain threshold [J] Journal of Physical Therapy Science, 2015, 27 (6), 1743-1745.

[25] Kim, S.-E., Kim, J.-W., \& Jee, Y.-S. Relationship between smartphone addiction and physical activity in Chinese international students in Korea [J] Journal of Behavioral Addictions, 2015, 4 (3), 200205.

[26] McGlinchey, E. L., Talbot, L. S., Chang, K.-hao, Kaplan, K. A., Dahl, R. E., \& Harvey, A. G. The effect of sleep deprivation on vocal expression of emotion in adolescents and adults. Sleep, 2011, 34 (9), 1233-1241.

[27] Lapierre, M. A., Zhao, P., \& Custer, B. E. Short-term longitudinal relationships between smartphone use/dependency and psychological well-being among late adolescents [J] Journal of Adolescent Health, 2019, 65 (5), 607-612.

[28] Alhassan, A. A., Alqadhib, E. M., Taha, N. W., Alahmari, R. A., Salam, M., \& Almutairi, A. F. The relationship between addiction to smartphone usage and depression among adults: A cross sectional study [J] BMC Psychiatry, 2018, 18 (1).

[29] Elhai, J. D., Dvorak, R. D., Levine, J. C., \& Hall, B. J. Problematic smartphone use: A conceptual overview and systematic review of relations with anxiety and depression psychopathology [J] Journal of Affective Disorders, 2017, 207, 251-259.

[30] Ratan, Z. A., Zaman, S. B., Islam, S. M., \& Hosseinzadeh, H. Smartphone overuse: A hidden crisis in covid-19 [J] Health Policy and Technology, 2021, 10 (1), 21-22.

[31] Li, L., Niu, Z., Mei, S. The Mindfulness CognitiveBehavioral Group Therapy of Medical Students' Smartphone Addiction in Group Counseling Course [J] China Higher Medical Education, 2017, (5), pp. 37-38

[32] Lan, Y., Ding, J.-E., Li, W., Li, J., Zhang, Y., Liu, M., \& Fu, H. A pilot study of a group mindfulnessbased cognitive-behavioral intervention for smartphone addiction among university students $[\mathrm{J}]$ Journal of Behavioral Addictions, 2018, 7 (4), 11711176.
[33] Kim H. Exercise rehabilitation for smartphone addiction $[\mathrm{J}]$ Journal of exercise rehabilitation, 2013, 9 (6), 500-505. 